Por uma (nova) psicopatologia da infância e da adolescência Kamers, M., Mariotto, R. M. M., \& Voltolini, R. (Orgs.) São Paulo, SP: Escuta, 2015, 320 p.

\title{
RETORNO AO NOVO. DE NOVO?
}

\author{
Ana Beatriz Coutinho Lerner
}

Michele Kamers, Rosa Mariotto e Rinaldo Voltolini, os organizadores desta coletânea de artigos, escolhem o significante novo para dar título a este livro, valendo-se de uma construção gramatical que opera tal como um apelo, um chamamento ao novo: Por uma (nova) psicopatologia da infância e da adolescência.

São vários os significados possíveis desse significante. Novo pode ser entendido como moderno, como outro, como aquilo que se ignorava, que se vê ou se ouve pela primeira vez, que ainda não serviu, aquilo que é recente, nascente, que existe há pouco. De novo: outra vez.

O que o uso do significante novo no título desse livro revela sobre os debates atuais em psicopatologia de crianças e adolescentes? $\mathrm{O}$ que estaria obsoleto e necessitaria ser renovado? O que é preciso introduzir de novo no campo do diagnóstico e do tratamento?

É na polissemia desse significante que o livro dá mostras de seu valor - por um lado, recuperando historicamente o que a psicanálise introduz de novidade no campo da medicina e da diagnóstica de uma época, isto é, em que o advento da psicanálise subverte a lógica médica do século XIX e início do século XX; por outro lado,

Psicanalista. Doutora em Educação pela Faculdade de Educação da Universidade de São Paulo. Psicóloga do Serviço de Psicologia Escolar do Instituto de Psicologia da Universidade de São Paulo/USP, São Paulo, SP, Brasil. 
apresentando o que é necessário trazer ao interior das discussões psicanalíticas: uma abertura ao diálogo, uma permeabilidade a outros saberes sem que tal movimento represente uma ameaça ou coloque em risco o "ouro da psicanálise". A psicanálise convocada a sustentar sua posição técnica, ética e política para trabalhar nas fronteiras pouco delimitadas entre o psíquico, o orgânico e o social.

Por último, mas não menos importante, o livro dá destaque ao essencial que é preciso ressaltar de novo: uma clínica do sujeito, sustentada em uma posição ética que considera a complexidade das operações constituintes do humano. Mais uma vez. Ainda.

O livro reúne quinze artigos de diferentes autores organizados em quatro partes: (1) Historia da psiquiatria, psicopatologia e psicanálise com crianças; (2) Diagnóstico, detecção precoce e tratamento; (3) psicopatologia, psicanálise e instituições; e (4) Psicopatologia e medicalização.

A primeira parte traz os artigos de Oscar Cirino, Maria Eugenia Pesaro, Leda Bernardino e Alfredo Jerusalinsky.

Cirino retoma as análises de psiquiatras e sociólogos sobre a formação do saber psiquiátrico a respeito da criança a partir de diferentes perspectivas de abordagem histórica. Nesse panorama, o autor destaca os processos de "medicalização da psiquiatria ou de sua dissolução no campo da neurologia" que acabam por reduzir o sujeito ao funcionamento de seu organismo, escamoteando "questões políticas, sociais, culturais e subjetivas que afligem a vida humana" (p. 32). Sua análise aponta a lógica predominante no discurso médico na contemporaneidade, que acaba por fomentar o exercício de uma "clínica da medicação que concede espaço apenas para as teorias comportamentais e cognitivas, excluindo a psicanálise como ultrapassada e ineficaz" (p. 37). Por fim, faz a defesa de uma abordagem "que não se restrinja, em nome da eficácia, à eliminação do sintoma através da medicalização" e que considere a "implicação subjetiva da criança com relação ao problema que ela traz e o envolvimento do Outro (família, escola, sociedade) que lhe concerne" (p.38).

Maria Eugênia Pesaro também segue a trilha histórica, mas no que se refere à construção do campo da psicanálise com crianças. A autora toma como eixo central de sua análise "os entraves teóricos e clínicos" lidos como sintomas que se presentificam na história da psicanálise (p. 41) e que, como tal, não param de produzir efeitos que podem fazer avançar o trabalho clínico com as crianças. Desses entraves, ela destaca a questão da analisabilidade de crianças, a 
transferência, o lugar dos pais na formação dos sintomas e na escuta analítica e a aliança nem sempre harmônica entre psicanálise e educação. Sustenta uma posição ética e técnica de "sustentação da criança-sujeito" a partir da consideração do sujeito como "um efeito das incidências e articulações dos discursos sociais, das funções materna e paterna e de uma singularidade que se apoia em uma corporalidade" (p. 51). Ao final, apresenta o Lugar de Vida - Centro de Educação Terapêutica como um espaço que inventa e cria com o infantil "para dar lugar de vida aos sujeitos" (p. 53).

Leda Bernardino adentra a complexa discussão sobre diagnóstico, estrutura e temporalidade na clínica com crianças a partir de duas questões norteadoras: "o psicanalista de crianças faz diagnóstico?” e “o psicanalista utiliza quais categorias psicopatológicas no que se refere à infância?" (p. 60).

Para desdobrar essas questões, Bernardino retoma o giro de diagnóstico para diagnóstica proposto por Dunker (2011), que marca a mudança de um ato específico de nomeação para um processo de atualização e transformação do diagnóstico “a cada novo tempo do tratamento e suas intercorrências". Bernardino afirma que esse giro é fundamental para o posicionamento do clínico "em se tratando de infância e adolescência, tempos gerúndios em que as operações psíquicas da constituição do sujeito ainda não se efetivaram" (p. 58). Por fim, conclui que o psicanalista faz, a partir de sua escuta, uma leitura do "andamento do processo de constituição subjetiva da criança", tendo em vista seu posicionamento como sujeito ou como objeto do Outro. Disso decorre uma concepção das categorias psicopatológicas (neurose, psicose e perversão) que leva em conta a diferença entre organizações defensivas transitórias no tempo da infância e a efetivação mesma da estrutura.

Alfredo Jerusalinsky faz uma crítica contundente ao discurso reducionista que tende à negação da influência do psiquismo nas patologias que acometem o sujeito. Vale-se de uma discussão com a genética para destacar que, mesmo no interior das ciências médicas, não é possível desconsiderar a incidência do entorno na determinação do curso das psicopatologias, a não ser que paguemos o alto preço da extinção da clínica. Se somos feitos de carne e linguagem, como negligenciar os efeitos da posição do sujeito nesse entrecruzamento das determinações orgânicas, pulsionais e sociais?

No estudo dos autismos - propositadamente no plural para assinalar a diversidade do que foi assimilado a esse diagnóstico nos manuais psiquiátricos contemporâneos -, Jerusalinsky deriva a discussão para as escolhas terapêuticas, ressaltando a importância do trabalho na direção da construção de significações que ajudem a criança 
autista a "lutar contra seus automatismos e entrar em relação com o mundo e com as pessoas" (p. 92). Nesse sentido, o autor traz fragmentos de sua clínica com crianças e dá mostras, mais uma vez, de seu estilo e inventividade.

A segunda parte do livro, "Psicopatologia: diagnóstico, detecção precoce e tratamento", traz os textos de Julieta Jerusalinsky, Ângela Vorcaro, Salmo Raskin e Cristina Kupfer.

Julieta Jerusalinsky situa a primeira infância como um importante momento de abertura às inscrições psíquicas, à plasticidade neuronal e a experiências da epigenética" (p. 114). Destaca que, ainda que certas patologias imponham limites orgânicos inexoráveis, "as experiências de vida podem produzir mudanças significativas diante de um mesmo quadro orgânico". Faz um alerta a respeito de duas lógicas que estão presentes nas intervenções precoces, tanto no campo médico como no psicológico, nos tempos atuais: a conduta expectante - na qual os agentes de saúde esperam até que os sinais de uma determinada patologia estejam mais evidentes para indicação de tratamento - e o furor diagnóstico, que tende ao fechamento e à patologização. Nessa perspectiva, a autora propõe a escuta do sofrimento presentificado no bebê e em suas famílias e o acolhimento destes no interior de uma clínica interdisciplinar que permita intervir no sentido de favorecer sua constituição subjetiva.

Ângela Vorcaro apresenta com rigor alguns paradoxos de uma psicopatologia psicanalítica de crianças. Seu texto dialoga com os outros autores presentes nesse eixo do livro, à medida que ela aponta "o que há de problemático na consideração das estruturas fixas em bebês, crianças e jovens" (p. 117). A autora parte da tensão epistemológica entre duas hipóteses sobre a constituição psíquica no interior da psicanálise: a condição estrutural do sujeito, determinada bastante precocemente em termos das primeiras marcas psíquicas e das vicissitudes da passagem pelo estádio do espelho e pelo Complexo de Édipo, em contraposição à ideia de "não decidido da estrutura no tempo da infância" (p. 117), portanto de relativa abertura aos acontecimentos e desastres da experiência de cada um. A autora parte da sustentação de uma posição ética do analista para afirmar que "a demarcação diagnóstica de uma estrutura clínica é capaz de produzir resistência suficiente para impedir a escuta de um inconsciente que resvala às classificações que o pré-concebem" (p. 118). Ela transita pela discussão sobre a demanda endereçada ao analista pelo corpo social e pelos pais, sobre a interrogação a respeito da forma como

238 Estilos clin., São Paulo, v. 21, n. 1, jan./abr. 2016, 235-244. 
a criança é interpretada pelo Outro em tempos de patologização da infância e de criação de uma infância ideal; discute a singularidade, isto é, como cada sujeito responde e se posiciona diante dos significantes que recolhe do campo do Outro, como constitui em si a alteridade diante das contingências que encontra, e como o analista comparece com sua escuta e seu ato, tomando a criança como enigma.

O texto seguinte, "Genética e psicanálise: um encontro possível?", é de Salmo Raskin, um geneticicista brasileiro membro da equipe do Projeto Genoma que, em 2003, publicou a versão definitiva da sequência do genoma humano, depois de 13 anos de árduas pesquisas. Nesse artigo, o autor nos presenteia com uma metáfora bastante ilustrativa que dá a ver a dimensão da complexidade envolvida nos estudos sobre o humano. Para ele, desvendar "o livro da vida" é como ter em mãos uma enciclopédia de 23 volumes, que conteria três bilhões de letras, sem a separação em parágrafos ou sinais de pontuação, e ainda sabendo que $99 \%$ das letras podem não significar nada. Os vinte três volumes seriam nossos cromossomos e cada capítulo seria um pedaço do DNA. Nas palavras do autor, é algo como ter "um tesouro riquíssimo na mão" sem poder "compreender e desfrutar da mensagem que este livro tem para ensinar" (p. 52).

Salmo destaca a ambição científica de encontrar respostas para os enigmas mais cruciais da humanidade - "De onde viemos? Quem somos? Para onde iremos?” (p. 150) - e revela o alcance e as limitações desse empreendimento. Para ele, o projeto Genoma Humano trouxe benefícios para milhões de pessoas, mas também gerou frustração e derrubada de alguns paradigmas que orientavam o saber médico até então. Um primeiro desdobramento dessas pesquisas é a descoberta de que "a complexidade de uma espécie não é diretamente proporcional ao número de genes", já que temos uma quantidade de genes semelhante à das minhocas: golpe certeiro em nosso narcisismo, talvez semelhante àquele empreendido por Freud com a descoberta do inconsciente e a afirmação de que não somos senhores em nossa própria casa. Outro ponto interessante é a descoberta de que $80 \%$ das sequências de DNAs não são propriamente genes, mas têm a função de produzir moléculas de RNA que são regulatórias dos genes e que sofrem efeito dos estímulos ambientais. Isso é de fundamental relevância à medida que traz à tona a importância das interações entre gene e ambiente, "só que desta vez, estas interações teriam uma base fisiológica” (p. 163), podendo inclusive ser transmitidas de geração para geração. Tal afirmação nos remete inequivocamente à 
tese freudiana das séries complementares anunciada nos "Três ensaios sobre a teoria da sexualidade", em 1905, e retomada em "A dinâmica da transferência", de 1912, e nas conferências de 1916-1917.

Uma última questão que gostaríamos de destacar é que, ainda que o estudo do genoma humano tenha possibilitado "identificar e esclarecer com enorme precisão a causa de cerca de três mil doenças monogênicas" (p. 154), no que se refere às doenças geneticamente complexas - entre elas as doenças psiquiátricas como autismo e esquizofrenia -, é possível afirmar que o Projeto Genoma parece não ter oferecido as respostas esperadas, o que deixa em aberto a pergunta: "onde está escondida a maior parte da herdabilidade?” (p. 162).

Cristina Kupfer fecha esse eixo do livro com um texto que aborda o impacto do autismo no mundo contemporâneo. A autora faz um arrazoado sobre o autismo do ponto de vista psiquiátrico e psicanalítico, destacando "as formas de compreensão de sua gênese e as modalidades de tratamento" (p. 170). Da perspectiva psicanalítica, Kupfer extrai operadores de leitura e importantes instrumentos para operar na clínica com crianças autistas que desarranjam a própria psicanálise de seu lugar de conforto, convocando-a para as fronteiras de seu campo de saber, especialmente na interface com a educação. Seus mais de vinte anos de experiência levamna a enfatizar a construção do prazer compartilhado, o estabelecimento do laço social ou de enlaces possíveis, a "construção de um lugar de enunciação no campo da palavra e da linguagem"1 e a emergência de efeitos de sujeito como a direção da cura no autismo. Cristina é um exemplo ímpar de uma clínica que não cessa de se reconstruir e de se afirmar na pólis, apesar dos impasses institucionais, políticos e sociais que concorrem para que ela se extinga.

O terceiro eixo reúne trabalhos que dão testemunho de uma clínica que estende sua ética às instituições educativas, de saúde mental na infância e à instituição familiar.

Voltolini segue a trilha de seus últimos trabalhos, interpelando "eticamente os fundamentos centrais do

240 Estilos clin., São Paulo, v. 21, n. 1, jan./abr. 2016, 235-244. 
discurso inclusivo nos dias de hoje" (p. 188). Para ele, o discurso inclusivo segue dois princípios: a crença no direito como regulador das relações entre os homens na direção de uma suposta harmonia e igualdade, e a crença na administração como paradigma da execução da justiça e do bom funcionamento das instituições. Ao propor uma vida assim concebida e administrada, o discurso inclusivo mostra desconsiderar a natureza da dinâmica dos conflitos sociais e acaba por fomentar práticas fadadas ao fracasso.

Marise Bastos revisita os fundamentos da Educação Terapêutica e faz importantes avanços teóricos nessa concepção de tratamento, que inclui o acompanhamento da escolarização de crianças autistas. A autora coloca lado a lado, ou melhor, em relação de continuidade, o ato analítico e a chamada "primeira educação" na condução da cura que orienta essa clínica. Sua proposição teórica parte da figura topológica da banda de Moebius - apresentada por Lacan no Seminário "A identificação" - para afirmar que "práticas analíticas e educacionais não são disjuntas" (p. 213), ainda que preservem sua especificidade, e que é possível tratar educando e educar tratando.

O belo caso clínico que a autora apresenta evidencia a força de um trabalho com a escrita tomada em uma determinada posição que excede a finalidade pedagógica de ensino do código alfabético e a situa como ferramenta terapêutica, capaz de operar no ordenamento do gozo, na construção de um lugar de enunciação para o sujeito, e como operação significante na direção da construção de um contorno possível para o real. Exercício clínico da melhor espécie marcado pela abertura à criação e invenção animadas pelo desejo de analista.

Daniela Teperman contribui com a importante discussão sobre a instituição familiar e a ordem sexual na nossa época, destacando na obra de Lacan e de outros autores contemporâneos a discussão sobre estrutura e função, não redutíveis às condições sociais ou aos papeis sociais desempenhados pelos pais em cada período da história. Para ela,

o irredutível da transmissão não reside no fato de que haja um homem e uma mulher no exercício das funções e tampouco a existência de pai e mãe conforma naturalmente - instintivamente - as operações fundamentais necessárias à constituição subjetiva. ... O que está em jogo para o sujeito é se o Outro Parental exerce sua função de posse de um desejo não anônimo, oferecendo-se como suporte concreto para que o sujeito possa se constituir como desejante. (p. 230) 
Dessa forma, insere a psicanálise nos debates atuais sobre gênero e sobre novas configurações familiares de forma não normativa e não acachapante dos vários arranjos possíveis da não relação entre os sujeitos.

Luciano Elia fecha a terceira parte do livro com um texto sobre o trabalho em equipe nos Centros de Atenção Psicossocial (CAPs). Luciano é uma figura absolutamente relevante para o movimento de implementação dos CAPs no Brasil, e sua atuação e produção revelam um compromisso clínico e político com a reforma psiquiátrica e com a sustentação desse dispositivo institucional da atenção psicossocial no cenário brasileiro.

O texto tem início com uma provocação instigante: "qualquer coletivo de profissionais, de caráter multiprofissional, ainda que bastante integrado e bem formado tecnicamente, pode ser chamado, a rigor, de equipe no sentido da atenção psicossocial?" (p. 243). Apoiado no conceito de coletivo de Oury, Elia vai apresentar o que considera os eixos constitutivos de uma equipe de CAPs: organizar-se como um coletivo $^{2}$ - e não como um grupo -, sustentar um lugar transferencial de escuta e seguimento do trabalho psíquico dos pacientes e assumir a responsabilidade por esse lugar na lógica e na ética do coletivo.

Ao afirmar a necessidade de um espírito psicossocial, seu trabalho carreia uma crítica contundente ao esvaziamento da clínica e à pregnância do diagnóstico e da aplicação de técnicas de tratamento nos dispositivos de saúde mental na atualidade. Faz um apelo para tomarmos

a tarefa da saúde mental para além de suas fronteiras sanitárias, incluindo em seu campo a relação dos que sofrem com o laço social, nele situando a posição de sujeito que eles assumem e agindo de modo a afetar esta posição, sempre na ampliação dos horizontes territoriais, as cidades que cada sujeito constrói para si em um mesmo espaço social. (p. 251)

O eixo final do livro reúne artigos sobre psicopatologia e medicalização da infância, destacando seus efeitos sobre a escola.

Michele Kamers parte da constatação do "aumento no número de diagnósticos na infância e a consequente medicalização da criança em idade escolar" (p. 267) e revela seu espanto diante da dificuldade de fazer frente a essa tendência, em que pese a extensa e já consagrada literatura crítica produzida a esse respeito, que não cessa de denunciar os limites dessa concepção de homem e de mundo. A autora segue a trilha dos diagnósticos para encontrar pistas que

242 Estilos clin., São Paulo, v. 21, n. 1, jan./abr. 2016, 235-244. 
auxiliem na compreensão do sofrimento das crianças na atualidade. Sua tese é a de que os diagnósticos de desatenção, hiperatividade, impulsividade e oposição, entre outros, captam e decodificam o que em psicanálise poderíamos chamar de modalidades de defesa diante do que se revela como um imperativo no discurso parental e social: "adapte-se, seja feliz, nos faça feliz ou te devoramos!"

Rosa Mariotto interroga-se sobre "o lugar ocupado pelo discurso médico nos laços discursivos em que a criança está inserida (família e escola)" (p. 296) e sobre qual a posição do sujeito nesse discurso. A autora recorre à discussão sobre transtorno e estrutura, introduz uma discussão, apoiada em Dunker (2011), sobre a especificidade do diagnóstico em psicanálise, e dá destaque a uma lógica diagnóstica em que estejam implicadas: transferência, escuta, hipótese e direção de trabalho. Para ela, trata-se de "escutar o lugar da criança no que se refere ao desejo, ao gozo e ao ideal dos pais e de que modo ela se situa nessa história: alienada, em separação ou separada" (p. 299).

O texto de Renata Guarido compartilha da crítica ao movimento de medicalização da infância a analisa os fundamentos dessa lógica, situando o remédio como um "objeto que atende ao desejo de resolução imediata dos conflitos da vida" (p. 306) e a criança como suporte do ideal parental de não haver restrições às suas próprias satisfações. Para a autora, revisitar a própria noção de sofrimento psíquico concorreria para fazermos "resistência a que os sintomas de um sujeito sejam tomados somente como sinais de uma doença" (p. 311). Uma leitura de fôlego, que acena de modo contundente para algo (ainda) necessário de ser sustentado no discurso social, tal como faz o poema "O novo homem", de Drummond, cujos trechos reproduzo aqui - infelizmente, em formato diferente do original, pelo pouco espaço de que dispomos nesta resenha.

O homem será feito / em laboratório, / muito mais perfeito / do que no antigório. / Dispensa-se amor, / ternura ou desejo. / Seja como flor / (até num bocejo) / salta da retorta / um senhor garoto. / Vai abrindo a porta / com riso maroto: / "Nove meses, eu? / Nem nove minutos." / Quem já conheceu / melhores produtos? / A dor não preside / sua gestação. / Seu nascer elide / o sonho e a aflição. / Nascerá bonito? / Corpo bem talhado? / Claro: não é mito, / é planificado. / Nele, tudo exato, / medido, bem-posto: / o justo formato, / o standard do rosto. / Duzentos modelos, / todos atraentes. / . . . Perdão: acabou-se / a época dos pais. / Quem comia doce / já não come mais. / Não chame de filho / este ser diverso / que pisa o ladrilho / de outro universo. / Sua independência / é total: sem marca / de família, vence / a lei do patriarca. / Liberto da herança / de sangue ou de afeto, / desconhece a 
aliança / de avô com seu neto. / Pai: macromolécula; / mãe: tubo de ensaio / e, per omnia secula, / livre, papagaio, / sem memória e sexo, / feliz, por que não? / pois rompeu o nexo / da velha Criação, / eis que o homem feito / em laboratório / sem qualquer defeito / como no antigório, / acabou com o Homem. / Bem feito. (Andrade, 1970/2016).

\section{REFERÊNCIAS}

U Andrade, C. D. (2016). Caminhos de João Brandão. São Paulo, SP: Companhia das Letras. (Trabalho Q original publicado em 1970)

Dunker, C. I. L. (2011). Estrutura e constituiçâo da clínica psicanalítica. São Paulo, SP: Annablume. Freud, S. (1980). Três ensaios sobre a teoria da sexualidade. In S. Freud, Edição standard brasileira das obras psicológicas completas de Sigmund Freud. (J. Salomão, trad., Vol. 7, pp. 129-255). Rio de Janeiro, RJ: Imago. (Trabalho original publicado em 1905)

- Artigos sobre a técnica: A dinâmica da transferência. In S. Freud, Edição standard brasileira das obras psicológicas completas de Sigmund Freud. (J. Salomão, trad., Vol. 12, pp. 133-143). Rio de Janeiro, RJ: Imago. (Trabalho original publicado em 1912)

. Conferências introdutórias sobre a psicanálise. In S. Freud, Edição standard brasileira das obras psicológicas completas de Sigmund Freud. (J. Salomão, trad., Vol. 16, pp. 503-521). Rio de Janeiro, RJ: Imago. (Trabalho original publicado em 1916-1917)

\section{NOTAS}

1. Referência à definição já consagrada de "educação" proposta por Leandro de Lajonquiére em vários de seus livros e artigos.

2. Para o autor, coletivo é uma coleção de agentes que se articulam como fragmentos, sem amalgamarem-se em um conjunto de idênticos e sem formarem um todo unido em torno de um líder, "mas orientados por um desejo comum" (p. 245).

anabcoutinho@yahoo.com.br

R. Dep. Lacerda Franco, 300/37

05418-001 - São Paulo - SP - Brasil.

Recebido em dezembro/2015. Aceito em março/2016.

244 Estilos clin., São Paulo, v. 21, n. 1, jan./abr. 2016, 235-244. 